\title{
The Study on the Welfare Effect of the Agricultural Insurance on the Farmers
}

\author{
Lv Liu \\ School of Insurance \\ Central University of Finance and Economics \\ Shahe Town, Changping District, Beijing \\ China \\ Zhang Yanli \\ Huang Qingjie \\ North China Institute of Aerospace Engineering \\ Central University of Finance and Economics \\ Shahe Town, Changping District, Beijing \\ China
}

\begin{abstract}
Agricultural production depends on natural conditions and is vulnerable to the influence of nature. Every year, due to the influence of natural disasters, many agricultural producers fall into poverty. Agricultural insurance is the most effective tool to manage agricultural risk. Agricultural insurance can provide farmers with post-disaster compensation, guarantee farmers' family consumption and recovery production, and bring welfare effects to farmers. In recent years, for the development of agriculture, banks have been implemented to provide loan services to farmers. Under the dual role of insurance and loan, the welfare effect of farmers has been greatly increased.
\end{abstract}

Keywords: Agricultural Risk; Agricultural Insurance; Welfare Effects

\section{Introduction}

China is a big agricultural country, always adhere to agriculture as the basis. But every year, due to floods, frost, drought, hail and other natural disasters, agricultural production is greatly hit. Farmers who depend on agricultural production for a living try to find that they are unable to earn agricultural income and fall into poverty. If no measures are taken to combat agricultural risks, the number of people living in poverty will continue to increase. Then we need to find effective measures to combat agricultural risks in order to increase the welfare effect of farmers.

The most effective way to combat agricultural risk is agricultural insurance. The agricultural insurance provides the "protective umbrella" for the agricultural producers, and provides the guarantee for the agricultural production of the farmers. Insurance has a positive impact on the GDP of the European countries and has contributed to the economic growth of the member countries of the European Union (Haiss P et al.2008). The agricultural insurance provides compensation for the future income of the farmers, and has a protective effect on the assets of the farmers. Promote the active agricultural production of the farmers, improve the production mode of the farmers, and improve the welfare of the farmers.

The financial sector has also improved the welfare of agricultural producers. On the one hand, financial institutions, such as banks, promote the production of agricultural production and promote agricultural income by providing loans for farmers, promoting the use of high-quality fertilizers and seeds, and improving the production technology; and on the other hand, farmers can use loans to purchase agricultural insurance, To compensate for the post-disaster economy, the post-disaster agriculture has a certain buffering effect. In recent years, the insurance industry has actively cooperated with the local government and the credit institution, and constructed the "political and silver protection"related micro-loan model, which solved the problem of the lack of financing collateral for farmers. In this paper, the numerical simulation method is used to explain the impact of insurance and credit on the welfare utility of farmers.

\section{Literature Review}

Insurance occupies a major position in a country's economy, and its utility in dealing with risks can not be ignored. he growth rate of the insurance industry will increase by $1 \%$, which will drive the real GDP growth rate to increase by $1.215 \%$ (Zhao Shangmei, et al.2009. 
Insurance reduces the impact of risk on economic fluctuations, plays a moderating role in the stable development of the national economy, reduces individual losses, and stabilizes individual household income (Shao Quanquan et al.2017). Insurance shortens the time of economic volatility after the disaster and reduces the number of people trapped in poverty ((Chen Guojin et al.2014). TChanaat S et al. (2017) said that livestock insurance promoted the well-being of the population in the northern part of Kenya, using data to model the dynamic wealth of the family in the north of Kenya, with the result that livestock insurance has improved the well-being of the population in the north of Kenya, which has played a role in reducing poverty.

Microcredit makes the performance of Nanzhao County in Henan Province increase by every year(Deng Guoji et al.2014) .

Lu Hao et al. (2019) selected the data of credit cooperatives in 31 regions of China, and found that rural microcredit can not improve the welfare effect of farmers, but also play a role in promoting the profitability of credit cooperatives.Li Xuetao et al.(2015) used the data of more than 500 households in Hubei Province to draw the conclusion that credit has a positive correlation effect on farmers' production and consumption, which promotes the economic income of farmers and improves the welfare level of farmers.

The model of "microcredit+microinsurance" can reduce the joint risk of farmers, financial institutions and insurance companies, insurance can promote the scale of credit, credit can promote the risk loss of insurance industry (Li Ziqin,2010). The cooperative model of "Credit + Insurance" has played an active role in the cooperation of innovative banks and insurance companies, not only providing support for farmers' financial resources, but also providing risk prevention services to farmers(Qiu Feng,2013).

\section{Model}

This paper considers that a rural family only gets income from agricultural production. At the same time, the risk input is determined by itself, and the risk of production is determined by the level of risk input. The marginal output of traditional production technology is small (low efficiency) and the risk is low; the marginal output of high technology is large (high efficiency), but it will bring greater risk and also need silent cost. In order to highlight the defects of credit market and the impact of insurance on risk management, this paper first models in a determined environment, and then models in an environment full of uncertainty. The following is the modeling process:

a: no credit, no insurance

b: only credit

c: only insurance

d:credit and insurance

\section{1 no credit, no insurance}

In this paper, a rational individual with infinite life span and agricultural production is considered. The asset starting in period $\mathrm{t}$ is $A_{t}$, Of which $x_{t}$ is the amount put into agricultural production, the output is $g\left(x_{t}, \varepsilon_{t}\right), \varepsilon_{t}$ is the risk. The remaining consumption is: $c_{t}=A_{t}-x_{t}$. The utility is $u\left(c_{t}\right)$, The asset for the $t+1$ period is:

$$
A_{t+1}=A_{t}+g\left(x_{t}, \varepsilon_{t}\right)-x_{t}-c_{t}+\gamma x_{t}
$$

The above can be abbreviated as follows:

$$
A_{t+1}=g\left(x_{t}, \varepsilon_{t}\right)+\gamma x_{t}
$$

The benefits of agricultural production are:

$$
y_{t}=g\left(x_{t}, \varepsilon_{t}\right)-x_{t}+\gamma x_{t}
$$

The consumption is determined after the production input. The consumption is limited to the sum of the actual income and the asset value after the end of the period t. That is:

$$
A_{t}+g\left(x_{t}, \varepsilon_{t}\right)-x_{t}-c_{t}+\gamma x_{t} \geq 0
$$

So the Berman equation, which represents the maximization of individual lifetime utility, is as follows:

$$
V\left(A_{t}\right)=\max E_{t}\left[u\left(c_{t}\right)+\delta V_{t+1}\left(A_{t}+g\left(x_{t}, \varepsilon_{t}\right)-x_{t}-c_{t}+\gamma x_{t}\right)\right]
$$

s.t. $A_{t}+g\left(x_{t}, \varepsilon_{t}\right)-x_{t}-c_{t}+\gamma x_{t} \geq 0$

\section{2 only credit}

Credit is an indispensable part of agricultural production, and the lack of funds will cause obstacles to farmers' agricultural production. Without funds to support the progress of agricultural technology, without funds to provide agricultural means of production, farmers' income can not be stable, or even fall into poverty. 
When farmers carry out agricultural production, they can lend to banks and other financial institutions and repay them at the end of the period. The loan amount of an individual is a certain proportion of his or her own capital, The interest on the loan is $r$.

The Berman equation, which maximizes the lifelong utility of individuals with credit, is as follows:

$$
\begin{gathered}
V\left(A_{t}\right)=\max E_{t}\left[u\left(c_{t}\right)+\delta V_{t+1}\left(A_{t}+g\left(x_{t}+\varphi A_{t}, \varepsilon_{t}\right)-x_{t}-c_{t}+\gamma x_{t}-(1+r) \varphi A_{t}\right)\right] \quad \text { (5) } \\
\text { s.t. } \quad A_{t}+g\left(x_{t}+\varphi A_{t}, \varepsilon_{t}\right)-x_{t}-c_{t}+\gamma x_{t}-(1+r) \varphi A_{t} \geq 0
\end{gathered}
$$

\subsection{Only agricultural insurance}

Agricultural insurance can stabilize farmers' agricultural production and make economic compensation for agricultural losses after disasters.

If there is no agricultural insurance, when agriculture is affected by hailstones, droughts, floods and other natural disasters, farmers' agriculture may not have any economic income, so they will fall into poverty. In this paper, individuals can buy enough agricultural insurance, then enough to buy agricultural insurance, the individual lifelong utility maximization Belman equation is:

$$
V\left(A_{t}\right)=\max \left[u\left(c_{t}\right)+\delta V_{t+1}\left(A_{t}+g\left(x_{t}\right)-\pi-x_{t}-c_{t}+\gamma x_{t}\right)\right]
$$

s.t. $A_{t}+g\left(x_{t}\right)-\pi-x_{t}-c_{t}+\gamma x_{t} \geq 0$

Of which, the premium is $\pi=p\left(g\left(x_{t}\right)-g\left(x_{t}, \varepsilon_{t}\right)\right), p$ is the probability of risk occurrence, if the risk occurs, $g\left(x_{t}\right)$ is the agricultural production without risk, the indemnity shall be as follows: $g\left(x_{t}\right)-g\left(x_{t}, \varepsilon_{t}\right)$.

\section{4 credit and insurance}

In recent years, in order to encourage and stabilize agricultural production, many places have carried out cooperation between banks and insurance institutions, which has achieved great results. Agricultural insurance only compensates for the losses suffered by farmers and does not bring additional property to farmers, but through bank loans, it can inject fresh blood into farmers' production, improve farmers' agricultural input, and improve farmers' agricultural income. If insurance and credit are tied together, one to manage risk and the other to inject money into agricultural production will further enhance the welfare of farmers.

Then, the Berman equation for maximizing the lifetime utility of individual farmers under insurance and loan is:

$$
V\left(A_{t}\right)=\max \left[u\left(c_{t}\right)+\delta V_{t+1}\left(A_{t}+g\left(x_{t}+\varphi A_{t}\right)-x_{t}-c_{t}+\gamma x_{t}-(1+r) \varphi A_{t}-\pi\right)\right] \quad(7)
$$

s.t. $\quad A_{t}+g\left(x_{t}+\varphi A_{t}\right)-\pi-x_{t}-c_{t}+\gamma x_{t}-(1+r) \varphi A_{t} \geq 0$

\section{Table 1 : Parameter Setting}

\begin{tabular}{|l|l|l|}
\hline Parameter & parameter name & parameter value \\
\hline$g\left(x_{t}\right)$ & output & $g\left(x_{t}\right)=x^{\beta}$ \\
\hline$\beta$ & Production elasticity & 0.5 \\
\hline$A_{t}$ & Initial assets & {$[4,12]$} \\
\hline$x_{t}$ & Agricultural production capital & $x_{t}<A_{t}$ \\
\hline$c_{t}$ & consume & $c_{t}=A_{t}-x_{t}$ \\
\hline$u\left(c_{t}\right)$ & utility & $u\left(c_{t}\right)=c^{1-\alpha} / 1-\alpha$ \\
\hline$\alpha$ & & 0.2 \\
\hline$\gamma$ & relative risk aversion & 0.9 \\
\hline$r$ & capital survival rate & 0.2 \\
\hline$\varphi$ & interest rate & 0.4 \\
\hline$\pi$ & lending ratio & $\pi=p\left(g\left(x_{t}\right)-g\left(x_{t}, \varepsilon_{t}\right)\right)$ \\
\hline$\varepsilon_{t}$ & premium & 0.1 \\
\hline$\delta$ & production shock volatility & 0.9 \\
\hline
\end{tabular}




\section{Result}

According to the formula (4)、(5)、(6)and (7)and the parameter setting of the table 1, the utility level of the life-long utility maximum level of the individual farmers is the figure1.It can be seen from Fig.1 that, with the dual role of insurance and credit, the life-long utility of individual farmers is the biggist.

As can be seen in Figure 2, the size of agricultural investment by farmers is the largest in the case of credit and insurance.

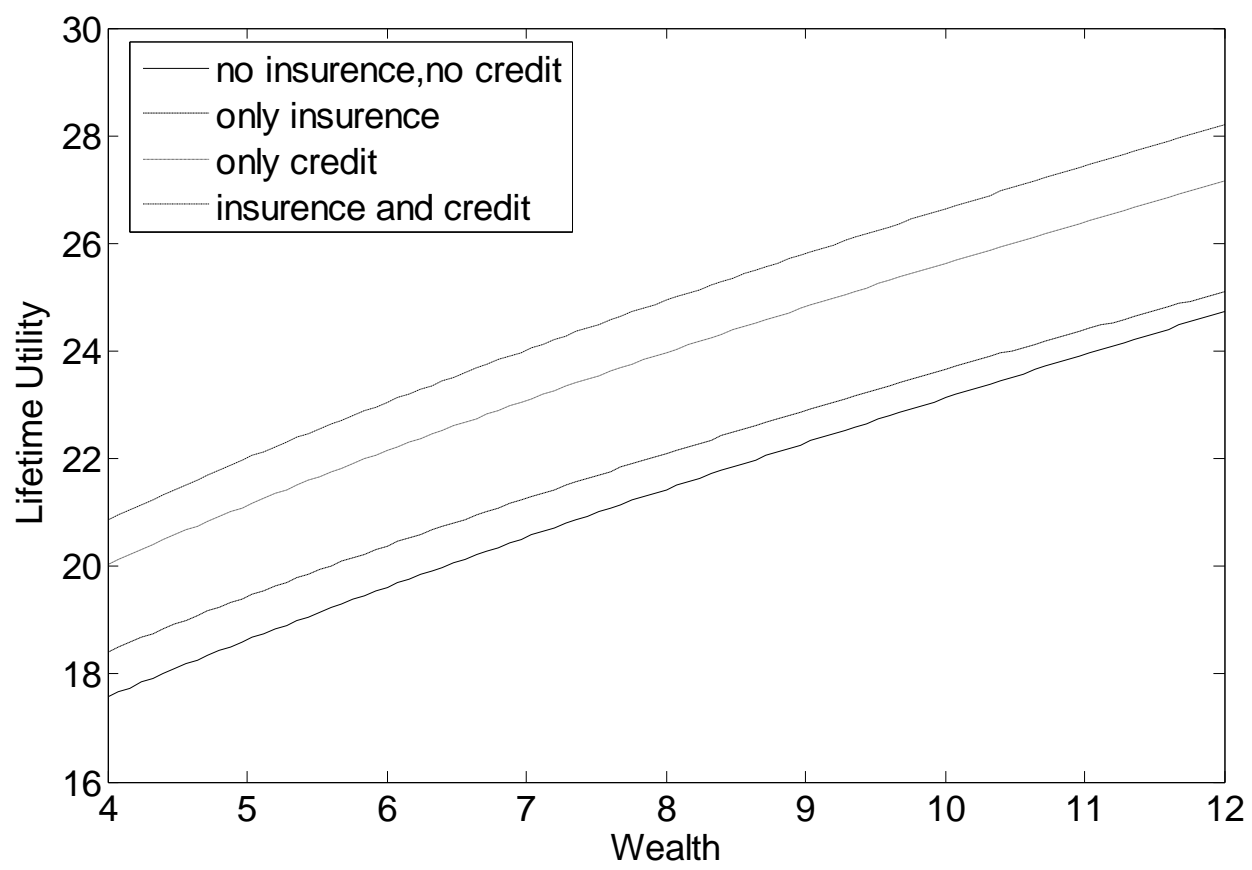

Fig.1 The lifelong utility of individuals in different situations



Fig.2 Optimal Investment Strategy under different conditions

\section{Empirical analysis}

In order to test the welfare effect of agricultural insurance on the residents of our country, this paper defines the people whose income is below the poverty alleviation standard stipulated in our country as the poor population, and the number of people below the poverty standard is: 


$$
N=4800 \int_{0}^{y}\left[\frac{(y-x)}{y}\right] f(x) d x
$$

Of which, $y$ indicates the poverty line ,This paper uses Xu Jianguo (2000) to analyze 4800 families in China, and obtains the logarithmic positive distribution function of per capita income distribution at the significant level of $5 \%$. $u$ is the logarithm of income, $\sigma$ is the variance of income.

$f(x)=\frac{1}{\sqrt{2 \pi} \sigma x} e^{-\frac{1}{2 \sigma^{2}}(\log x-u)^{2}}$

Table 2 shows the annual poverty alleviation standard in China, and the people whose income is below this standard are poor.

Table 2: poverty criteria

\begin{tabular}{|l|l|l|l|l|l|l|l|l|l|}
\hline year & 2009 & 2010 & 2011 & 2012 & 2013 & 2014 & 2015 & 2016 & 2017 \\
\hline $\begin{array}{l}\text { Poverty } \\
\text { Standard } \\
\text { (RMB })\end{array}$ & 1067 & 2300 & 2536 & 2625 & 2736 & 2800 & 2855 & 3000 & 2300 \\
\hline
\end{tabular}

The number of people living in poverty calculated on the basis of formula (8) is shown in table 3 , from which it can be seen that the synergy between insurance and credit has led to a significant decline in the number of people living in poverty.

Table3: Number of people living in poverty

\begin{tabular}{|l|l|l|}
\hline Different situations & $\begin{array}{l}\text { Number of people living in } \\
\text { poverty }\end{array}$ & $\begin{array}{l}\text { Comparison with basic } \\
\text { conditions(4800) }\end{array}$ \\
\hline No insurance,no credit & 4800 & ---- \\
\hline Only insurance & 3216 & -1584 \\
\hline Only no credit & 2352 & -2448 \\
\hline Insurance and credit & 1344 & -3456 \\
\hline
\end{tabular}

Note: the number of credits is the poverty standard 625RMB for the year of 2000.

\section{Conclusion}

The insurance is used for the management of the agricultural risk of the farmers, and the credit provides the financial resources for the agricultural production of the farmers to improve the technology. The common effect of the two is that the welfare of the farmer is the most. In order to stabilize the agricultural economy and promote the development of agriculture, the insurance company can cooperate with the bank to realize the win-win of farmers, insurance companies and banks.

\section{Reference}

Chantarat S , Mude A G , Barrett C B , et al(2017). Welfare Impacts of Index Insurance in the Presence of a Poverty Trap[J]. World Development, 94.

Chen Guojin, Chao Jiangfeng, Wu Xiaoli, et al(2014). Rare disaster risk and China's macroeconomic volatility [J]. Economic Research,8:54-66.

Deng Guoji, Che Shu, Meng Xiaoyu(2014). A study on the Social performance Evaluation of Rural Microcredit: a case study of Nanzhao County Microcredit Poverty Relief Society [J]. Western Finance, 3: 87-90.

Haiss P , Kjell Sümegi(2008). The relationship between insurance and economic growth in Europe: a theoretical and empirical analysis[J]. Empirica, 35(4):405-431.

Li Xuetao, Gong Dehua( 2015). The influence of supporting lending behavior on farmers' income and welfare levelbased on the survey data of farmers in Hubei Province [J]. Hubei Agricultural Science, 5: 262-267.

Li Ziqin(2010). Research on the establishment of "microcredit microinsurance" dual-drive model [J]. China's national conditions and national strength, 7: 25 (27).

Lu Hao, she Yujuan(2019).Analysis on the impact of microcredit business on the performance of rural credit cooperatives [J]. Journal of Chongqing Institute of Science and Technology (Social Science Edition),254 (01): $62-63+71$.

Qiu Feng(2013). A study on the coordinated Development of Rural Microcredit Insurance [J]. International Finance, 2.

Xu Jianguo(2000). Income Distribution and growth Model of durable Consumer goods [M]. 
Ye Minghua, Wei Yue(2015). Agricultural Insurance and Rural Credit: Interactive Model and Performance Evaluation [J]. Economic System Reform,5:92-97.

Zhao Shangmei, Li Yong, Pang Yufeng(2009). The theoretical model and empirical test of the contribution of insurance industry to economic growth[J]. Insurance Study,1:51-56.

Shao Chuan, Wang Bo, Bai Longfei(2017). Risk shock, Insurance guarantee and Macro-economic fluctuation in China [J]. Financial Research,6: 5 -20. 